\title{
THE
}

6-16-2019

\section{The creativity of imitation in remake videos}

Renee Hobbs

Harrington School of Communication and Media, University of Rhode Island, hobbs@uri.edu

Yonty Friesem

Follow this and additional works at: https://digitalcommons.uri.edu/com_facpubs

The University of Rhode Island Faculty have made this article openly available.

Please let us know how Open Access to this research benefits you.

This is a pre-publication author manuscript of the final, published article.

Terms of Use

This article is made available under the terms and conditions applicable towards Open Access

Policy Articles, as set forth in our Terms of Use.

\section{Citation/Publisher Attribution}

Hobbs, R., \& Friesem, Y. (2019). The creativity of imitation in remake videos. E-Learning and Digital Media, 16(4), 328-347. https://doi.org/10.1177/2042753019835556 
CITE AS: Hobbs, R., \& Friesem, Y. (2019). The creativity of imitation in remake videos. E-Learning and Digital Media, 16(4), 328-347.

\section{PRE-PUBLICATION COPY}

\section{The Creativity of Imitation in Remake Videos}

When attending a youth media screening event in Philadelphia in 2013, many attendees were impressed by a short video screened there, entitled "Love Language." The short video depicts a unique relationship that develops between two young people sitting on a park bench through the use of post-it notes. We see the couple flirting and developing an interest in each other over a period of three days as they playfully exchange notes. At the conclusion of the short film, it is revealed that one of the youth is hearing and one is deaf. The charming and sentimental narrative offers an optimistic view of human nature and human relationships and expresses people's ability to communicate and value each other across difference. The video received an audience appreciation award at the youth media screening event hosted at PhillyCam, the city's local access center.

But only one week previous to this event, in Providence, Rhode Island, the GiveMe5 festival, a state-wide youth media event, featured another youth-produced video, also called "Love Language," featuring different actors and setting, but with an identical plot, structure, and form. This video also received a warm response from the audience. Because the ending credits were cut before the conclusion of the film, the audience could not see that this version included a line at the end that indicated that the productions were in fact a remake of the viral video produced by the Jubilee Project to support the American Society for Deaf Children in November, 2010. A search on "Love Language" on YouTube reveals thousands of short video remakes from around the world featuring the plot and structure of the original. It is difficult to determine why this video attracted so many imitations, but the simple production values and emotionallycompelling narrative may explain its popularity as an object of imitation.

We take an interest in the "Love Language" video in order to examine some of the pleasures, paradoxes, and tensions regarding the ethical, aesthetic, and therefore educational values of youth-produced remake videos. Although remakes have been sometimes considered "uninspired copies," the remake genre is a significant part of filmmaking (Koos \& Forrest, 2002, p. 3). Film critics of the mid- $20^{\text {th }}$ century considered remaking a purely American practice, a product of standardized filmmaking practices and the monopolization of the world market. In distinguishing between film remakes and adaptations, film scholars considered remakes as films that simply updated an older film in order to maintain its appeal to new audiences, while adaptations made changes to the content and form of the original in a way that transforms it by adding new meaning and value (Koos \& Forrest, 2002). In examining Hollywood film remakes, Lenos (2009) observes that film remakes capitalize on familiarity while adapting narrative and filmic tropes to new cultural contexts.

Digital remix practices work in similar ways to link together media culture, history and locality, often as a form of social critique (Jocson, 2013). In an analysis of YouTube videos that generated a high volume of derivatives, Shifman (2011) noted that memetic YouTube videos used both imitation (careful copying elements from another video) and remix (re-editing an original video to create new meaning). In the context of YouTube, remake videos are creative 
derivatives that generate user engagement by adapting content primarily from a single earlier video, making variations while ensuring that the remake is recognizably similar to the original. Thus, remake videos exploit the popularity of the original, as "the number of derivatives spawned by a certain video is an indicator of attention, and in turn draws attention to the memetic video, in a reciprocal process" (Shifman, 2011, p. 199).

As youth media production grows, there is some concern about youth voice and issues of originality, copyright, and reproduction of media culture, values, and norms (Halverson, 2010; Hauge, 2014). But there is much pedagogical value in the act of imitation; copying is itself a time-honored form of education practice (Duncum, 2009). At the same time, creativity is understood as the process of modifying and adapting previously created content and form to create novel and original material (Ferguson, 2016). Creative media professionals acknowledge that constraints and limitations of the production process often create conditions where creativity can flourish. Media educators may want to encourage the creation of remake videos or discourage this practice, depending on their attitudes and beliefs about imitation and originality (Masterman \& Thompson, 1980).

In this paper, we situate a focus on the "Love Language" phenomenon in relation to the literature on YouTube culture, youth media, media literacy, and media arts education. In order to understand the dialectic tension between imitation and originality, we conducted a content analysis of "Love Language" remake videos to examine filmmakers' copying of narrative content, stylistic format, and cinematography in the creation of remake videos. By exploring the relationship between imitation and originality, we consider the creativity of imitation and reflect on its implications and potential consequences in relation to the pedagogy of youth media, media arts education, and media literacy education.

\section{Literature Review \\ Theories of Imitation in Education}

What is the relationship between creativity, copying, imitation and learning? Imitation, as a practice of learning, has sometimes been treated with disrespect. Since Plato, people have considered art as an imitation of nature and thereby inferior to the original. The Greek philosophers debated the role of imitation in the artistic process. Some thought that art was successful if it depicted a unified, single action as a complete whole, seeing the artist as abstracting reality from a close encounter with nature (Sullivan, 1989).

Imitation has a place in learning, however. Some in the ancient world thought that artists should look to human life and character for inspiration, imitating great artists and gaining familiarity with their best works. According to some scholars of classical rhetoric, imitation facilitates both critical analysis and creative practice in the context of learning. In studying the writings of Cicero, Aristotle, Quintillian, and others, scholars have identified differences of emphasis on the relative value of pedagogical practices of imitation such as memorization, translation, paraphrasing, and modeling (Sullivan, 1989). Modeling was often used as part of pedagogy in the ancient world. During the phase of learning called analysis, "students, under the guidance of the teacher, made a close study of the model to observe how its excellences followed the precepts of art" (Corbett, 1971, as quoted in Sullivan, 1989, p. 11). In the learning phase called genesis, students attempted to create something similar to the model that had been analyzed. For generations going far back before the Renaissance, educators have emphasized the practice of children analyzing and copying approved models as a means to learn. Imitation was thus deeply rooted in respect for the accomplishments of the past. 
Attitudes about the value of imitation for developing a creative mind changed as a result of $18^{\text {th }}$ century Romanticism, which conceptualized creativity as the work of an individual genius who sees reality in new ways. As works of the past were considered increasingly outdated and inferior, educators were less likely to hold them up as worthy of emulation (Duncum, 1988). Imitation because suspect among educators and artists who believed that only by breaking with the past can fresh insights emerge. In the 1960s, when the forward-looking energy of youth culture created deep ruptures with the past, the concept of imitation fell under deep suspicion. Activities and lessons that encouraged imitation were thought to deny creative self-expression to the learner. During this time, "no one argues in favor of imitative procedures in the literature of art education," as art educators firmly believed that imitation "deprives the child of flexibility, destroys his imagination, injures his self-confidence, and makes him dependent" (Bagley, 1963, p. 8). Personal imagination, life experience, and memory were thought to be the only meaningful inspiration for creative work.

Some scholars have examined imitation in relation to social practices. Of course, scholars have long recognized that most creative innovations build upon the "the grace of culture, i.e., man's pooled learnings" (Bagley, 1963, p. 10). As anthropological studies developed new insights on the relationship between language, culture, and learning, scholars began to understand that imitation served a fundamentally social and communicative purpose (Hyde, 2010). Walter Benjamin also explored the nature of imitation in relation to the sociology of language, noting that imitating and producing sounds through language is a manifestation of the deep psychic ties that bind us to ourselves and others (Benjamin, 1986/1936). Imitation is a set of creative practices that enable humans to make themselves similar to their environments through assimilation and play (Benjamin \& Tarnowski, 1979). As Puetz (2002, p. 1) notes, "Through physical and bodily acts of mimesis (i.e. the chameleon blending in with its environment, a child imitating a windmill, etc.), the distinction between the self and other becomes porous and flexible."

Thus, issues of imitation also raise questions about social power. Schools, in particular, use various forms of pedagogic action to disguise the arbitrary and unequal distribution of cultural resources in society (Bourdieu \& Passeron, 1990). In Horkheimer and Adorno's Dialectic of Enlightenment (2002), they claim that mimesis has been repressed in Western history, making art the last refuge for making ourselves seem similar to others through physical and symbolic acts of imitation. Through examining imitation, scholars began to question the relationship between a symbolically-generated world to and a real world, identifying how power relationships are embedded in the practice of representation (Horkheimer \& Adorno, 2002).

Scholars in media studies underlined the point that popular culture reinforces dominant social values while simultaneously offering pleasures associated with resistance to and even subversion of the social order (Storey, 2003). Building upon the work of Michel de Certeau, Jenkins (2012/1992) showed how fan audiences were engaged in "textual poaching" through their re-interpretation and appropriation of media texts that demonstrated the cultural power of the active audience. Through the production of fan fiction and other forms of creative derivative work, ordinary people participate in the gift economy and help democratize culture (Hyde, 2010). Perhaps for this reason, media arts educators have for generations seen their students copy or re-create scenes or characters from contemporary movies, music, and TV shows in their own creative work (Masterman \& Thompson, 1980). Some educators have conflicted attitudes about the value of remakes; many struggle with the tensions between copying, originality, and 
creativity (Ferguson, 2016). Copying can be an inspiration to deepen creative practice, as Gardner (1980, p. 194) has argued, where models are viewed as "helpful guides rather than dictatorial masters." It may also provide an authentic audience for young people, making youth media production a more meaningful learning experience that advances a sense of civic agency and civic responsibility (Levine, 2008).

Many art teachers understand that students may simply copy or imitate popular culture texts because these cultural resources resonate on an emotional or spiritual level with their own lived experience. As Duncum (2009, p. 233) explains, while both "conformity and transgression mark the mass culture of television and cinema, advertising, magazines, and so on," when people create their own media, they also play with these tensions, sometimes reinforcing gender, racial, ethnic, and other inequalities.

Legal theorists and philosophers have made similar arguments about the value of copying as a creative practice that advances knowledge, builds creative confidence, and supports the transmission and sharing of ideas. Since the early 1990s, the American legal system has recognized that transformative use of copyrighted material is fully protected by copyright under the doctrine of fair use (Hobbs, 2010). When authors make unauthorized use of copyrighted materials in their own creative work, without paying a license fee or asking permission, they may transform the copyrighted work by giving it new meaning through new context or purpose. Strategic copying can be therefore understood as a form of practice that can promote creativity. In examining the role of copyright and fair use in media education, Harvard legal scholar Rebecca Tushnet asserts that copying can be a powerful form of self-expression. Through an analysis of the speeches of Dr. Martin Luther King Jr. and other rhetors, she demonstrates that "copying that is part of an interpretive project often has a transformative purpose" (Tushnet, 2018, p. 27).

Finally, copying may promote confidence in self-expression. Learning to represent the physical world through drawing, painting, sculpture, or the media arts forces the learner to recognize their own choices and strategies as they make reference to the existence of something else (Laybourne \& Cianciolo, 1978; Niesyto, Buckingham \& Fisherkeller, 2003). The imaginative expression of children and teens cannot occur outside of cultural contexts that contain countless potential influences, including peers, parents, and media. As Ernst Gombrich (1977, p. 33) has noted, an artist "cannot transcribe what he sees; he can only translate it into the terms of his medium."

\section{Remake Video Genres}

We use the term remake video with awareness that the terminology for the different forms of YouTube videos is still emerging in the scholarly community as new and modified types of video emerge. The concept of collective cultural production has been used to describe the way in which people respond and react to YouTube videos by creating parodies, imitations, and commentaries (Strangelove, 2010). The remake video genre is an artifact of participatory culture (Jenkins, et al., 2009), where low barriers to artistic expression and civic engagement combine with strong support for creating and sharing one's creations, supported by apprenticeship-type learning experiences.

Scholars have applied structuration theory to understand how people acquire a form of agency that enables them to act upon the world and choose to reproduce, tinker with or alter the dominant forms of expression in their cultural environment. Structuration suggests that human agents perpetually produce, reproduce and transform social institutions through various cultural practices (Giddens, 1984). In digital scholarship, the concept of the meme hinges upon the notion 
of virality, where the spread, distribution, replication, and propagation of memes occur through social networks (Shifman, 2011). For example, Wiggins and Bowers (2014) claim that memes follow a pattern of genre development that includes stages of maintenance, elaboration, and modification. In the maintenance stage, creators adhere to the rules for creating the genre without altering the genre. In the elaboration stage, they make slight adjustments to the genre. In the modification stage, circumstances emerge that demand a substantial and consistent departure from existing genre rules, leading creative individuals to intentionally modify a genre.

People are motivated to copy, imitate, or respond to videos that have achieved popularity because spreadability is a new type of commodity in the context of digital culture (Jenkins, Ford \& Green, 2018). Researchers have examined the role of video sharing and video creation as a type of collective behavior, building upon on the work of Herbert Blumler (2007) who recognized that communicative actions serve to create and maintain norms and social practices. As people are able to use the Internet to gain knowledge of others, pay attention to them, and consider their own lives in relation to others, collective behavior may increase people's sense of connectedness, social power, and control.

Remake videos enable people to participate in a type of online conversation. In an analysis of 132 YouTube videos created in Hong Kong about the Bus Uncle, a viral video featuring man whose talk and behavior on a public bus captured the public imagination in 2006, one researcher found "that the pattern of uploads showed that there was a period in which users were creating posts specifically to become part of a discussion" (Chu 2009, p. 350).

Seeing remake videos as part of the process of genre formation, we can understand how numerous types of videos spawn imitations in ways that lead them to become generic. For example, unboxing videos depict a person opening a toy or digital device, documenting the process and reviewing the product. After the first unboxing video was created in 2006 for the Nokia E61 cell phone (Amien, 2015), many people imitated this new genre. By January 2019, the term unboxing videos yielded over 144 million results. Many other videos have been imitated widely, including pranking videos (Hobbs \& Grafe, 2015), soldier welcome home videos, nonsuicidal self-injury or self-harm videos, and many more.

Some remake videos are explicitly framed around a particular social cause. Perhaps the most well-known remake imitation video is the 2014 "Ice Bucket Challenge" which featured an individual who pours a bucket of ice on themselves and then challenges three other people to repeat and copy the action and document it on video. This phenomenon was designed to increase awareness and support fundraising for research on ALS, a debilitating neurodegenerative disease that affects 6,000 people each year. The phenomena that started on live TV spread through social media and included more than 2.4 million videos on Facebook tagged as the "Ice Bucket Challenge" (van der Linden, 2017). As of January 2019, a Google video search on the keyword "ice bucket challenge" yielded 6.27 million results. Many were created by celebrities and politicians, and this fundraising effort raised more than $\$ 100$ million in the US and worldwide (ALS Association, 2014). In this case, the pay-it-forward purpose seems to creates a viral genre of advocacy using imitation as a challenge to continue civic engagement through a cycle of media production and consumption.

Other remake videos seem to valorize diversity and cultural adaptation and specificity in an explicit way. For example, the "Harlem Shake" was a 30-second video created in 2013 and featuring electronic dance music by Baauer. One person dances alone, surrounded by other people unaware of the dancing individual. The video then cuts to a group of dancers flailing and making convulsive movements. The simple production of the "Harlem Shake" as well as the 
contradictions in the two parts of the video made it popular as a form of transgression to showcase misbehavior and sexual context in daily settings. While some attributed the virility of the "Harlem Shake" to YouTube monetizing by corporations (Ashton, 2013), others note that the simple production values allowed marginalized groups to have a voice and representation online (Steele, 2013). These remakes included adaptations involving teenagers playing video games, undergraduates in their dorms, athletes in the field, to various army units.

Finally, some remake videos revolve around offering an intimate and highly personal message of empowerment. Sometimes, these feature an easy to imitate template that features simple production values with little need for editing. Self-disclosure videos use confession style "card story" using cards with hand-written text inspired by Bob Dylan's "Don't Look Back" film trailer (Court \& Grossman [producers], 1967) where he holds and reveals a sequence of handwritten cards with simple phrases. When Kieran Miles created a video called ' 10 Reasons to Smile' and Jonah Mowry created 'Whats Goin On ...' (August 10, 2011), they inspired others to use note cards with hand-written text presented sequentially to self-disclose their health and relationship struggles. Consistent with the collective behavior described by Chu (2009), some examples of this genre appear as a type of dialogue, where one creator is responding to a previously viewed example by creating an imitation.

Some remake imitations go viral while others do not. Little is known about why some remake videos achieve virality. For example, because Ben Breedlove died from heart disease only two weeks after posting "This is My Story" (Dec 18, 2011) as an answer to Kieran Miles' video, his video received considerable attention in mainstream media, which helped it reach a large audience. Similarly, growth of this genre increased after the suicide of Amanda Todd, who posted her version of a card story video called "My Story: Struggling, Bullying, Suicide and Self-Harm" (September 7, 2012) where she disclosed and reflected on being a victim of bullying (Misoch, 2014). More and more teenagers used the note cards as a means to reflect on negative experiences and use video self-expression as a coping mechanism (Hall, 2016). Continuing a long tradition of remakes in folk culture (Lenos, 2009), it seems that video producers on YouTube adjust the content and form of their creative work to changing cultural trends and social issues, aiming to increase the popularity or visibility of their work or to address particular communities of interest.

\section{The "Love Language" Video and its Remakes}

Our interest in the many imitations of the "Love Language" video comes from its combination of simple format and sentimental emotional valence which combine narrative storytelling with disability awareness goals. These content and format features may have particular relevance and utility for youth media practitioners, media arts, and media literacy educators.

As we described in the opening pages, the short story features a budding romance between two Asian-American teens (one hearing and one deaf). The original video version of "Love Language" was uploaded to YouTube by the Jubilee project (Jason Y. Lee, Eddie Lee, and Eric Lu) in Nov 2, 2010. It has received over 3.7 million views (as of January 2019). Within three months, a remake imitation was uploaded, using an identical shot sequence, with the same music, similar acting and shot composition, and same props. The video entitled "(REMAKE) Love Language" was uploaded on Feb 22, 2011, and since then it has received triple the number of views (10.5 millions views as of January 2019).

Why did the remake get far more visibility than the original? Remakes are not just created for self-expression or cultural participation. They are also created with an eye towards 
the acquisition of likes, fame, and wealth. By exploiting the popularity of the original video, the remake may be aiming to displace (or replace) the original in the competitive algorithmic context of YouTube. The first video, created by the Jubilee Project, seems to be shot with a high-quality camera, with careful use of lighting, exposure, and shot composition. The sound design seems to have been mixed professionally to balance ambient sound, voice, and music.

By contrast, although the remake is visually similar, with identical shot structure and storyline, the image and sound quality is much lower. The remake has overexposed lighting, less experienced actors, audible hiss sounds, and less professional use of subtitles. The filmmaker who created the remake clearly marked the production as an imitation, putting an embedded link in the description section beneath the YouTube video and linking to the original video created by the Jubilee project. Therefore, it is highly likely that the first remake inspired more imitations than the original work.

\section{Research Questions}

The aim of this study was to better understand the interplay between imitation and originality in the "Love Language" remake videos by analyzing the content, format and cinematography in order to consider their potential value as an instructional practice for media arts and media literacy education. A careful study of the many "Love Language" remake videos may shed insight on the creativity of imitation activated as young people exercise the technical skills of video production, advance competencies of creative self-expression, and seek fame and wealth by competing for audience attention through creating a remake of an already-popular video. We asked these research questions:

RQ1: How is narrative content, character identity, and the setting of "Love Language" imitated in the remake videos?

RQ2: How is format and cinematography imitated in the remake videos?

RQ3: What is the relationship between imitation and originality in "Love Language" remake videos?

\section{Method}

We conducted a content analysis involving the systematic categorization and counting of recurrent elements in the form and content of 94 "Love Language" videos in order to examine the particular interplay between imitation and originality that exist in this corpus of artifacts.

Sampling. We used the phrase "love language" in YouTube, which yielded 80,200 items. To reduce the dataset, we added the term "short film" to discover 187 items, filtering results using uploaded date instead of the automatic relevance feature on YouTube. We counted videos from August 26, 2017 to November 2, 2010, when the original Jubilee Project "Love Language" video was uploaded to YouTube. After reviewing videos, we excluded 93 videos that were either duplicates of previous versions, blooper, or behind the scenes videos of making "Love Language" or unconnected to the original narrative with its themes of budding romance and disability awareness. Thus, our sample consisted of 94 "Love Language" remake videos.

Measurement of Variables. Since this study is examining close imitation as part of the cultural phenomenon of remake videos, variables examined key content and formal elements of the original "Love Language" video in order that a content analysis could enable us to see what proportion of the videos are faithful to the original. As we analyzed the video in relation to our research question, we identified 25 variables for analysis which are described below. 
Seven context variables included the URL, number of views, date of publication, YouTube user name (a proxy for creator), and the country of origin as evidenced by location information provided on the user's channel or other hints on the user's YouTube channel. We also coded to identify whether the video was produced as part of a formal education program or not, using evidence of the mention of a school or university, or reference to a school project or events. We also collected the description of the content as provided by the YouTube user who uploaded the video.

Seven character, content, and setting variables included: gender of actors, race/ethnicity of actors, actors' change of clothing as a device to indicate the narrative occurs on sequential days, presence of flirting behavior, use of post-it notes to exchange information between characters, the girl's use of finger spelling to communicate the message that she is deaf, and the boy's final note, "You're still beautiful." Setting variables included an outdoor setting, the use of a park bench where characters encounter and interact with each other.

Five format variables included the length of video, use of the original music, entitled, "Peaches by New Heights," the use of credits, the presence of bloopers (which were not included in the original video), acknowledgement of Jubilee Project in the credits or description as the inspiration, original, or source.

Seven cinematographic variables include: extreme close-up of foot tapping as the girl sits on the park bench, the use of jump cuts to communicate the boy's patience as he waits for the girl to arrive, the over-the-shoulder shot of the post-it notes, side-angle shot of the boy looking at the girl, extreme close up of sticky notes, the use of date slates to indicate the passing of time, the use of titles to capture spoken language.

Intercoder Reliability. Intercoder reliability was computed for 20 videos that were randomly selected from the data pool and coded independently by two coders. Some coding disagreements were discovered and handled by discussing and resolving disagreements, following by revision and clarification of the code book. After recoding an additional sample of 10 items which contained disagreements, high inter-coder reliability was achieved for all variables except country of origin. The Cohen's Kappa values for all binary categories ranged from .73 to 1 , indicating an acceptable level of intercoder agreement.

Data Analysis. The Jubilee Project video was defined as the original video upon which all other videos in the sample were compared. For the descriptive analysis of the data, the percentages of each binary variable were computed and interpreted. To explore the research question regarding imitation and originality, we created a ratio of imitation and originality that depicts the relationship between the number of videos that that used close imitation for particular features of each video as compared with those which contained original elements.

As mentioned earlier, more than potential 80,000 items were available on YouTube. Among the sample of 94 "Love Language" videos that we examined, the videos achieved 16 million views, a highly significant but not overwhelming level of attention. The number of video views ranged extremely widely from 10 to 10 million views. The mean number of views is 153,749 while the median is 1,097 and the standard deviation is $1,029,871$. The bottom quartile of videos had an average of 250 views, while the top quartile had an average of 8,273 views. As a result, our sample clearly included videos that were more (and less) viral, enabling us to examine a variety of remakes.

\section{Findings}

Imitation of Narrative Content, Character Identity and Setting 
We found substantial evidence to demonstrate a unique pattern of global transmission that centered around a number of countries particularly in North America and Southern Asia.

In exploring RQ1, we discovered that "Love Language" remake videos embody a global depiction of Asian identity. Clear evidence was found that the "Love Language" remake phenomenon is a global phenomenon, with YouTubers from 16 countries participating in the remake process. The popularity of "Love Language" remake videos appears to be centered primarily in North America, the Philippines and India. Together, these three countries represent $58 \%$ of the videos in our sample. Other countries include Indonesia, Australia, Bangladesh, Japan, Vietnam, China, Nepal, Russia, Turkey, Kazakhstan, and Egypt. We were able to identify the countries where each video was produced for $85 \%$ of the sample. Due to the limitations of analyzing a YouTube video, we cannot assume any other cultural or identity reference besides the labeled country of origin and the language in the video as posted on YouTube.

In reviewing the clues that indicate whether the video was part of a formal school project or informal learning activity, about half of the "Love Language" remake videos seem to have been produced directly for a class project. Evidence such as the name of the school, the name of the class or the name of the teacher could be seen in the closing credits or in the content description.

The "Love Language" video seems to be particularly relevant among people of Asian descent. In the original Jubilee Project, the boy and girl characters were both Asian-Americans. In analyzing the apparent gender, race and ethnicity of the remake videos, we found that all 94 videos included a boy-girl pair. In $61 \%$ of the videos, the boy and girl were both Asian. In 12\% of the videos, one member of the pair was Asian and in $27 \%$ of the videos, characters were not Asian. Thus, we conclude that "Love Language" video remakes embody a global Asian identity and as a YouTube phenomenon, the remakes have achieved a substantial level of visibility.

We found a bigger pattern of imitation of the original "Love Language" video rather than creating a transformative remix video inspired by the original video (see table 1 and 2 ). The sections below demonstrate the ratio between originality and imitation where the producers chose overwhelmingly to replicate the setting, context, formats, and cinematography. While the rest of the finding section focuses on the fidelity of the producers to imitate the original "Love Language" video, we wanted to examine the few who transformed the message and values by producing original remix video based of the original concept of boys meets deaf girl on a bench for three days in a row until they fall in love.

One "Love Language" video reversed the gender roles so that the boy was the deaf individual. Another video used the same narrative structure accompanied by an original song. The boy is depicted as a musician, with a guitar, and we understand him to be the author of the song, with the effect of transforming the genre from its original narrative into a music video. One Indonesian video depicts the boy as knowing from the beginning that the girl is deaf, with the romance depicted as a fantasy dream sequence that includes hyper-stereotypical romantic marriage proposal, followed by the dramatic wake-up scene where friends are pouring water on his head to wake him up. Such anomalies, while not very common in our dataset, demonstrate that some remake producers made plentiful use of creative freedom in the production process leaning toward remix rather than a remake video.

To explore the content and setting variables we created an imitation-originality ratio to examine the choices of the video creators who make creative decision about what to strictly imitate and what to alter, modify or change. Table 1 shows the data for these variables. 
Some content had a higher likelihood of being imitated and other behaviors were more likely to be adapted in an original manner. Most of the videos remained faithful to the use of clothing changes to signal that time has passed. Table 1 shows that 88 videos used this convention just as it was used in the original "Love Language" video and only 4 did not use this convention, resulting in an imitation-originality ratio of $22: 1$. Most videos used post-it notes to capture the dialogue between the boy and girl, with only 9 of 84 videos using varying other kinds of writing surfaces, resulting in an imitation-originality ratio of 28:3. Similarly, most videos featured the girl using fingerspelling to explain her deafness as well, with an imitation-originality ratio of 21:2.

Video creators showed originality in depicting the nature of the relationship between the characters. Lower ratio scores reveal the variables where the creators of the remake "Love Language" videos showed creative ways of depicting the dynamics between the two characters. For example, a ratio of 35:11 shows that 22 of 92 videos did not depict flirting between the boy and the girl. ${ }^{1}$ A number of video creators modified, adapted or changed the ending line of the video. A ratio of 77:16 shows that 16 videos did not use the ending line, where, after the girl reveals her deafness, the boy says to the girl, "You're still beautiful." Other modifications and changes made to the ending line included, "I still like you," "Will you be my girlfriend?" "I certainly didn't expect that," and "You are still perfect." In exploring RQ3, we will report more nuanced elements of originality in character identity and narrative conflict.

\section{PLACE TABLE 1 ABOUT HERE \\ $* * * * *$}

\section{Imitation and Originality in Format and Cinematography}

More originality was found in the format and cinematographic variables as compared with the narrative content and character variables. Format variables included the use of the original music, entitled, "Peaches by New Heights," the use of credits, the presence of bloopers (which were not included in the original video), acknowledgement of Jubilee Project in the credits or description as the inspiration, original or source. A large proportion of video creators diverged from the original "Love Language" video in their use of music. As the imitationoriginality ratio of 53:40 reveals, while 53 videos used the same music as the original, 40 videos used different music. Some videos used "Peaches by New Heights" and added music from other sources.

The original "Love Language" video did not include bloopers, so the imitation-originality ratio shows that 19 videos diverged from this path and added bloopers (typically of actors practicing, setting up a scene, or laughing at mistakes).

We found strong evidence of an ethic of acknowledgement, as most of the "Love Language" remake videos did make an effort to credit the original as a normative professional practice. Since the original production itself used credits, the imitation-originality ratio of 77:15 shows that only a small number of videos did not use credits. In this study, fully two-thirds of the videos included some form of acknowledgement. 34\% of videos had no acknowledgement of the original Jubilee Project while $21 \%$ of the videos in our sample acknowledged the original Jubilee Project in their credits. An additional 29\% included an acknowledgement in the description shown on the YouTube page and 13\% included acknowledgement in both the video and the description.

\footnotetext{
${ }^{1}$ It is possible that the quality of amateur acting performances affected coder interpretation.
} 
In order to explore whether the "Love Language" video was part of a film school training exercise, we measured seven cinematographic variables including the most distinctive visual codes used in the original remake. These included an extreme close-up of foot tapping as the boy waits on the park bench, the use of jump cuts to communicate the boy's patience as he waits for the girl to arrive, the over-the-shoulder shot of the post-it notes, side-angle shot of the boy looking at the girl, extreme close up of sticky notes, the use of date slates to indicate the passing of time, the use of captions to capture spoken language. Only a few cinematographic conventions were reproduced with fidelity by video makers. The most commonly imitated conventions include the close-up of writing, where the imitation-originality ratio reveals that 85 videos matched the look of this shot and only 7 diverged from this convention. Another commonly imitated convention was the use of date slates to indicate the passing of time. They generally took the form of "Day 1," "Day 2" and "Day 3." A imitation-originality ratio of 20:3 showed the common tendency of remake videos to replicate this convention.

Cinematographic conventions for shot composition, including the over-the-shoulder shot and the side-angle shot were less commonly found in the remake videos in our sample. An imitation-originality ratio of 18:5 for the over-the-shoulder shot and a ratio of 67:24 for the sideangle shot suggest that a large number of video creators did not imitate the shot composition techniques used in the original video. Even more variation was found in the use of certain editing conventions, including the close-up of a foot tapping, with a imitation-originality ratio of 19:27 and the jump cuts to indicate time passing, with an imitation-originality ratio of 27:19, as shown in Table 1. In the original Jubilee Project video, captions were used to transcribe spoken (and signed) language into written form. Among the 94 remake videos, only 63 retained this feature and 29 did not use captions.

\section{Originality in Remake Videos}

The large majority of remake videos imitate both the narrative content and the formal features of the originals, using the "disability reveal" as the surprise ending. But a number of remake producers altered elements of character identity, narrative content, and setting to creatively manipulate the characters and conflicts depicted in the narrative. For example, one "Love Language" video reversed the gender roles so that the boy was the deaf individual. In another, the boy is blind and the girl is deaf. A number of videos supplied additional information about the characters to deepen or alter the narrative. In one remake video featuring two AfricanAmerican teens, in the final scene, after the girl reveals her deafness, the boy writes, "You don't have to hear music to dance..." and then he takes her hand, pulling her to him in a romantic dance move. As the camera features their feet and their happy smiles in this final dance scene, the swelling music intensifies the sweetness of the sentimental and romantic ending.

A few remake producers used the "Love Language" narrative as an inspiration for adaptations that radically altered the mood and tone. In one video, we see a breakup of a young couple, near the ocean, followed by a lot of out-of-focus shots of the ocean accompanied with sad music. Then, scene two is the "Love Language" exposition handled in a manner nearly identical to the original, followed by scene three, which features the boy alone at the beach, with shots of a setting sun. This version frames the original happy ending of "Love Language" with a more melancholy wraparound that gives the effect of a flashback narrative structure, suggesting that happiness is fleeting and that isolation and sadness are represent a more natural state of being.

Other remake producers play with the visual depiction of the surprise relationship between the two characters, actually removing the disability theme from the story line. One 
video features a chance meeting between a boy and girl on a sidewalk. The girl, who is away at college, sits on bench and leaves a note there. The next day, there is a note is waiting for her. She writes notes and receives them, placing a small stone on the notes to keep them from blowing away. At no time do we know who she is communicating with. As the story continues, we see a shot of the notes floating in the air as the sun shines. Suspense mounts. Finally, the boy arrives on the park bench and they begin to talk. Here the remake video producer seems to be assuming that viewers are familiar with the "Love Language" video remake and is creating a version that features a relationship depicted through the creative absence of one of the main characters.

Some remake producers use the identity of the deaf girl and hearing boy as a jumping off point for the narrative but use none of the format or cinematographic elements of the original. In one video entitled, "The Language of Love," we meet a young Asian boy who is lonely at school and who seems to be ignored and bullied. He meets a deaf girl, but none of the narrative conventions of "Love Language" are used as their relationship develops- no post it notes, no jump cuts to indicate time, no headphones to indicate music playing. Instead, the relationship develops at various locations at school, where the boy and girl write on traditional school notebooks. When apart, they also use text messaging on their smartphones. When he plucks up his courage to ask her out, he composes a poster that says, "Date?" and practices with it in front of the mirror, using a variety of charming facial expressions. But just as he approaches the girl, another boy intrudes and rudely kisses the girl, causing her to fearfully run away. Heartbroken and confused, the boy returns to the classroom, only to discover the girl. He ignores her until she throws a chalk at him. Then he reveals his poster, and they embrace. The final slide reads, "Anyone who keeps the ability to see beauty never grows old." While the story and theme follow the "Love Language" video closely, the narrative execution is quite different. This video is the only one that came closest to being considered a film adaptation by maintaining essential plot elements but uses new representations of character, setting and conflict.

Some videos appeared to manipulate the genre of the video. For example, in one video, the boy is depicted as a musician with a guitar, and we understand him to be the author of the song that is playing in the audio track. This shift has the effect of transforming the genre from its original narrative into a music video. One Indonesian video depicts the boy as knowing from the beginning that the girl is deaf, with the romance depicted as a fantasy dream that includes hyperstereotypical romantic marriage proposal, followed by the dramatic wake-up scene where friends are pouring water on his head to wake him up.

Some videos remake through a bit of play with style, by gussying up the opening sequence or changing small elements of the format. One video features the boy bringing heartshaped post it notes on Day 3 as way to express his true feelings. Another remake uses a voiceover and text in the opening of the video, talking about how true love begins. We then see the name of the video production company. "Mystique Films" and the title of the video, "True Love," followed by opening credits listing the names of the actors. And although one video was a remake of "Love Language," its purpose was clearly as a classroom assignment where students were merely required to demonstrate the ability to speak and write in French. Produced by high school students for an introductory French foreign language class, these beginning speakers were practicing their French language skills rather than communicating any ideas about love, disability and the power of communication.

\section{Discussion}

Remake videos display a complex mix of originality and imitation in narrative content, format and cinematography. "Love Language" has both narrative content and structural features 
that make it an attractive target for remaking. The story line is of universal interest to teenagers and young adults because of the natural challenges involved in introducing yourself and getting to know a person you have just met. The sentimental depiction of budding romance and the surprise ending, where the viewer learned of a previously hidden or invisible disability inspire feelings of sympathy and appreciation. The simple set, limited use of spoken language, and short length of the video make it easy for young filmmakers to reproduce. As the content analysis revealed, many of the remake videos were strict imitations of the original, where it seemed like the expressive creativity was in duplicating with precision a shot-by-shot imitation of the original.

Clearly, awareness of the dialectic between imitation and originality is important for education in the creative arts (Burn \& Durran, 2007). Michelangelo's students learned to draw by copying his drawings and today's film students copy sequences from Star Wars just as, a generation ago, the French New Wave filmmakers like Jean Luc Godard were watching Hitchcock movies in the Parisian cinematheque and producing films that borrowed heavily from their format, content, and style. Strict imitation, however, might not activate creativity. Some might even question the creativity and value of strict imitation as a pedagogy of film education. Kirby Ferguson (2016), in explaining the popularity of "Star Wars: The Force Awakens" uses familiarity-novelty continuum to analyze the work of J.J. Abrams, who directed Lost, the new Star Trek and other films. Too much familiarity is boring, he explains, just as too much novelty is incomprehensible. Getting the balance right is the sweet spot in popular culture. As an example of this, in 1998, Gus van Sant's shot-by-shot remake of Hitchcock's Psycho was criticized as having little creative value beyond its function as a cinematic exercise.

The "Love Language" video relies on a flattering depiction of Asian youth, romantic relationships, and deafness. Although it originated in the United States, the phenomenon quickly spread to Asian countries where numerous remakes maintained the ethnic and racial identity of the original characters. The original video and the remakes all offered a representation of Asianness and deafness, which are both depicted as attractive and charming. Viewers see Asian teens acting like kind, sensitive and playful young people. Although it originated in the United States, the phenomenon quickly spread to Asian countries where numerous remakes maintained the ethnic and racial identity of the original characters.

The video remakes depicted characters as conventionally normative in terms of gender binary dynamics: the boy initiates the relationship, both the boy and the girl display shyness, anticipation, and flirting; he demonstrates commitment by waiting for her to return to the bench; she demonstrates shyness in at first hiding and then self-disclosing her deafness; and finally, at the conclusion of the video, he validates her identity through reference to her beauty. In each remake, the character's depiction of acceptance, validation, or approval relies on the written use of post-it notes.

While gender stereotyping is present, deafness is not presented as a handicap or deficiency in the "Love Language" videos. The depiction of deafness relies on one key scene presented at the conclusion of the story, when the film ends with the surprising revelation that the girl is deaf. When the boy first asks about the girl's music, she rejects his request to share the special song. The hiding of her deafness is further enabled by her use of earphones throughout the film and this justifies the couple's use of post-it notes for social interaction. The revealing moment, tenderly presented, occurs when the girl offers to share her special song. When the boy puts on her earphones, the non-diegetic music, "Peaches by New Heights" abruptly stops and the viewer comes to understand that the soundtrack of the video has been meta-diegetic, i.e., 
representing both the inner mind of the character and the ambient sounds in the fictional world. In addition to the creative use of music to reveal the girl's deafness, fingerspelling helps reinforce the moment when the girl explains her deafness. Throughout the video, the girl's deafness is not presented as a disability. Because the Jubilee Project aimed to increase awareness of deaf culture, the video represents the girl as an able person, one who flirts and interacts with hearing people as a part of daily life.

While the narrative includes a representation of disability, it also includes a potentially harmful gender stereotype in the boy's use of the phrase of approval, "You're still beautiful" as the final line of the video. The superficial value of feminine appearance over all other human values was conventionally reproduced in 77 of 93 videos. But a number of the remake videos changed the final line of the film, including such lines as "I still like you," "Will you be my girlfriend?" "I certainly didn't expect that," and "You are still perfect." We don't know how much discussion or debate occurred among members of the production crew, but we can assume that some filmmakers made strategic decisions in deciding to alter the fine line of the script. Changing a problematic representation to be less stereotypical is evidence of both creativity and critical thinking. Production teams who altered the script to be less stereotypical may have been able to analyze the original video, discuss and consider alternatives, and select from among the most appropriate and creative.

Close examination of the "Love Language" videos provides an opportunity to consider the ethics of acknowledgement. Two-thirds of remake authors offered some form of credit to the original work. It seems like many remake video producers understand their form of creativity as "standing on the shoulders of giants" and it is possible that producing this video activated a sense of agency through imitation. Among the remake productions that do not attribute the original Jubilee Project authors, all chose to use the name "love" and "language" in the title. Because our sampling strategy relied on the use of these words in the title, it is possible that we missed other videos that imitate the form and content without providing any attribution.

In reflecting on the strengths and limitations of this research, the imitation-originality ratio may be useful for other studies of remake videos and enable educators to support student reflection on the nature of creative expression. Perhaps the imitation-originality index will stimulate discussion, critical analysis and exploration of issues including representation, identity, and creativity in media production. Limitations of this study include one important challenge to the nature of sampling remake videos and, by extension, any study of imitation. We could not identify a search strategy that enabled us to include imitations which did not reference the original in one way or the other. It is possible that we missed some important "Love Language" remakes that did not turn up in our search. Thus, our findings may overstate the ethic of acknowledgement. Given the existing (generally negative) attitudes of educators (Duncum, 1988), critics and jury festival voters towards imitation, it is possible that some remake producers intentionally obscure the remake status of their work.

Cultural differences in attitudes about originality and imitation may also be likely explanations of the many cases in which remake producers did not use attribution. Because the videos come from 16 different countries, a limitation of this study was the inevitable biases introduced by the interpretive process, as we, the researchers, struggled to make sense of the sometimes unfamiliar contexts, situations, and narrative choices made by filmmakers. Since we could not conduct interviews of producers or observe the remake production process, our content 
analysis of the remake YouTube videos provides limited evidence of the potential educational value of remakes for media literacy education.

On the other hand, based on the literature review, we can identify three main reasons to copy the original version: (a) to exploit the popularity of the original video for oneself, (b) to master the craft of filmmaking, or/and (c) to align with an important and valued message. All of these reasons may align with the pedagogical goals of a media literacy educator. A media educator can teach the phenomena of viral video and cinematic techniques using a hands-on activity of remaking a simple video. By analyzing first the remake phenomena of "Love Language" followed by a creative media production reproduction activity, students can reflect on their media use as well as learn basic production skills of composing a YouTube video. A comparison contrast of two remake videos would permit careful examination of characters, conflict, format, and cinematography, using the imitation-originality index to note similarities and differences between two texts. A class discussion on the appeal of remake videos might elucidate the concept of transformative use, as remakes may copy the original for a range of creative purposes and goals. As students engage in analysis, discussion, and production they might better reflect on their own values and the way express them with a remake or remix video. By exploring remake as a genre, educators and scholars may be able to understand how the process of composing remake video may enhance students' media literacy competencies.

\section{Conclusion}

This research explored imitation and originality in remake videos, discovering that video producers manipulate the content, format, and cinematography in a complex blend. Using a ratio to depict the levels of imitation and originality for a small dataset of remake videos, we captured the complex dialectic present in the creator's choices. A ratio scale helps conceptualize dialectic between imitation and originality and this index may be useful in better understanding the potential virality of remake videos. But we see the primary value of a ratio scale to depict the imitation-originality dialectic in supporting the pedagogy of youth media production as media literacy education.

To acknowledge that imitation can be a form of creative expression is a paradigmshifting idea that challenges traditional concepts of digital citizenship, which emphasizes the social responsibility of avoiding plagiarism and copyright violation.

For students learning the craft of video production, the imitation-originality ratio may give the young producer a means to consider some fresh avenues for expressing creative vision and enabling artistic choices. Creating remake videos may be a valuable first step for learners who are intimidated by self-expressive activities (Friesem, 2015). Remake video production may be valuable to educators with diverse interests, including those who want to provide an introduction to cinematography, those curious about virality, and those exploring creative expression in the context of imitation and copying. Further research should examine the use of imitation as pedagogical strategy to support the process of critical thinking and creativity as part of media literacy education. 


\section{References}

ALS Association. (2014, August 29). The ALS association Expresses sincere gratitude to over three million donors. Retrieved from http://www.alsa.org/news/media/press-releases/icebucket-challenge-082914.html

Amien, D. (2014, October 10). Why Unboxing Videos Are So Satisfying. Retrieved from https://finance.yahoo.com/news/why-unboxing-videos-are-so-satisfying99561095209.html

Ashton, K. (2013, March 28). You didn't make the Harlem Shake go viral-corporations did. QUARTZ. Retrieved from https://qz.com/67991/you-didnt-make-the-harlem-shake-goviral-corporations-did/

Bagley, A. (1963). The Idea of imitation. Art Education, 16(4), 8-10. doi:10.2307/3190442

Benjamin, W. (1968[1936]). The work of art in the age of mechanical reproduction. In H. Arendt (Ed.), Illuminations (pp. 217-252). New York, NY: Shocken Book.

Benjamin, W., \& Tarnowski, K. (1979). Doctrine of the Similar (1933). New German Critique, (17), 65-69.

Blumler, H.G. (2007). The field of collective behavior. In J. Goodwin \& J.M. Jasper (Eds.)

Social movements: critical concepts in sociology (pp. XX - XX). London and New York: Routledge.

Bourdieu, P. \& Passeron, J. C. (1990). Reproduction in education, society and culture. Thousand Oaks: Sage.

Burn, A., \& Durran, J. (2007). Media literacy in schools: Practice, production and progression. London, UK: Paul Chapman.

Chu, D. (2009) Collective behavior in YouTube: a case study of 'Bus Uncle' online videos, Asian Journal of Communication, 19:3, 337-353, DOI: 10.1080/01292980903039038

Duncum, P. (1988). To copy or not to copy: A review. Studies in Art Education, 29(4), 203-210. doi:10.2307/1320922

Duncum, P. (2009). Toward a playful pedagogy: Popular culture and the pleasures of transgression. Studies in Art Education, 50(3), 232-244. Retrieved from http://www.jstor.org.uri.idm.oclc.org/stable/40650334

Friesem, Y. (2015). Digital empathy: Developing socio-emotional and cognitive skills using digital media. In S. Tettegah, \& D. L. Ferdig (Eds.), Emotion, technology and behavior. San Francisco, CA: Elsevier.

Ferguson, K. (2016). Everything is a Remix: The Force Awakens. Video. Available: https://vimeo.com/167069783

Gardner, H. (1980). Artful scribbles: The significance of children's drawings. New York: Basic.

Giddens A (1984). The constitution of society: Outline of the theory of structure. Berkeley, CA: University of California Press.

Gombrich, E. (1977). Art and illusion: A study in the psychology of pictorial representation London: Phaidon Press.

Hall, K. (2016). Selfies and self-writing. Television \& New Media, 17(3), 228-242. doi:10.1177/1527476415591221

Halverson, E. R. (2010). Film as identity exploration: A multimodal analysis of youth-produced films. Teachers College Record,112(9), 2352-2378. Retrieved from http://0www.tcrecord.org.helin.uri.edu/library/Content.asp?ContentId=15948 
Hauge, C. (2014). Youth media and agency. Discourse: Studies in the Cultural Politics of Education, 35(4), 471-484. doi:10.1080/01596306.2013.871225

Hobbs, R. (2010). Copyright clarity: How fair use supports digital learning. Thousand Oaks, CA: Corwin.

Hobbs, R. \& Grafe, S. (2015). YouTube pranking across cultures. First Monday, 20(7) https://journals.uic.edu/ojs/index.php/fm/article/view/5981/4699

Horkheimer, M. \& Adorno, T. W. (2002). Dialectic of enlightenment. Trans: G. Noeri. Stanford University Press.

Hyde, L. (2010). Common as air: Revolution, art, and ownership. Farrar, Straus and Giroux.

Jenkins, H. (2012). Textual poachers: Television fans and participatory culture. New York: Routledge.

Jenkins, H., Ford, S., \& Green, J. (2013). Spreadable media: Creating value and meaning in a networked culture. New York: New York University Press.

Jenkins, H., Purushotma, R., Weigel, M., Clinton, K., \& Robison, A. J. (2009). Confronting the challenges of participatory culture: Media education for the 21 st century. Cambrige: MIT Press.

Jocson, K. (2013). Remix revisited: Critical solidarity in youth media arts. E-Learning and Digital Media, 10(1), 68-82. http://dx.doi.org/10.2304/elea.2013.10.1.68

Koos, L. \& Forrest, J. (2002). Dead ringers: The remake in theory and practice (SUNY series, cultural studies in cinema/video). Albany: State University of New York Press.

Laybourne, K., \& Cianciolo, P. (1978). Doing the media: A portfolio of activities, ideas, and resources. New York, NY: Center for Understanding Media \& McGraw-Hill.

Lenos, M. (2009). Déjà vu: Cultural functions of Hollywood remakes. Doctoral dissertation, Temple University.

Levine, P. (2008). A public voice for youth: The audience problem in digital media and civic education. In L. W. Bennett (Ed.), Civic life online: Learning how digital media can engage youth. the john D. and catherine T. MacArthur foundation series on digital media and learning. (pp. 119-138). Cambridge, MA: MIT Press.

doi:10.1162/dmal.9780262524827.119

Masterman, L., \& Thompson, J. (1980). Teaching about television. London: Macmillan.

Miroch, S. (2014). Card Stories on YouTube: A New Frame for Online Self-Disclosure. Media and Communication, 2(1), 2-12.

Niesyto, H., Buckingham, D., \& Fisherkeller, J. (2003). Video culture: Crossing borders with young people's video productions. Television \& New Media, 4(4), 461-482. doi:10.1177/1527476403255813

Puetz, M. (2002) Mimesis. Theories of Media, Keywords Glossary. University of Chicago. Available: http://csmt.uchicago.edu/glossary2004/mimesis.htm

Shifman, L. (2011). Anatomy of a YouTube meme. New Media and Society 14(2), 187 - 203.

Storey, J. (2003). Inventing popular culture: From folklore to globalization. Malden: Blackwell.

Strangelove, M. (2010). Watching YouTube: Extraordinary videos by ordinary people. Toronto: University of Toronto Press.

Steele, C. K. (2013). Shaking off the 'Other': Appropriation of marginalized cultures and the 'Harlem Shake'. AoIR Selected Papers of Internet Research, 3. Retrieved from http://spir.aoir.org/index.php/spir/article/viewFile/838/pdf

Sullivan, D. (1989) Attitudes toward imitation: Classical culture and the modern temper. Rhetoric Review 8(1), 5-21. DOI: $10.1080 / 07350198909388875$ 
Tushnet, R. (2018). Mix and match: Transformative purpose in the classroom. In R. Hobbs (Ed), The Routledge companion to media education, copyright and fair use (pp. 22 - 30). New York: Routledge.

van der Linden, S. (2017). The Nature of Viral Altruism and How to Make it Stick. Nature Human Behaviour. 1: 0041. doi:10.1038/s41562-016-0041.

Wiggins, B. E., \& Bowers, G. B. (2015). Memes as genre: A structurational analysis of the memescape. new media \& society, 17(11), 1886-1906.

\section{Acknowledgements}

The authors would like to acknowledge research assistance from Nikita Duke, Kristen Beatty, Hongyan Lu, and Hacer Dolanbay at the Media Education Lab. 
Table 1

Imitation - Originality Ratios in "Love Language" Videos

\begin{tabular}{lccc}
\hline Content Variables & IMITATION & ORIGINAL & RATIO \\
\hline Change of Clothing & 88 & 4 & $22: 1$ \\
Flirting & 70 & 22 & $35: 11$ \\
Post-It Notes & 84 & 9 & $28: 3$ \\
& & & \\
Fingerspelling & 84 & 8 & $21: 2$ \\
You're Still Beautiful & 77 & 16 & $77: 16$
\end{tabular}

Setting Variables

\begin{tabular}{lccc}
\hline Outdoor & 86 & 8 & $43: 4$ \\
Bench & 72 & 21 & $24: 7$
\end{tabular}

Format Variables

\begin{tabular}{lccc}
\hline Music & 53 & 40 & $53: 40$ \\
Display of Credits & 77 & 15 & $77: 15$ \\
Bloopers & 72 & 19 & $72: 19$
\end{tabular}




\section{Cinematographic}

Variables

$\begin{array}{lccc}\text { Foot Tapping Close Up } & 38 & 54 & 19: 27 \\ \text { Jump Cuts } & 54 & 38 & 27: 19 \\ \text { Over-the-Shoulder Shot } & 72 & 20 & 18: 5 \\ \text { Side Angle Shot } & 67 & 24 & 67: 24 \\ \text { Close Up of Writing } & 85 & 7 & 85: 7 \\ \text { Date Slates } & 80 & 12 & 20: 3 \\ \text { Captions } & & & \\ \text { N = 93 } & 63 & & \end{array}$

